\title{
Jongerenrechtbanken: oplossingsgerichte lekenrechtspraak voor en door leerlingen
}

\author{
Gert Jan Slump en Jessica Asscher*
}

Sinds januari 2015 zijn op drie scholen in Amsterdam jongerenrechtbanken actief. ${ }^{1}$ Naar Amerikaans voorbeeld, waar Youth Courts ${ }^{2}$ al decennia bestaan, is een Nederlandse variant ontwikkeld. In 2017 sloot een vierde school zich aan. De Amsterdamse pilot duurt drie jaar en is volledig gefinancierd door private fondsen. Leden van de jongerenrechtbank zijn allemaal leerlingen van de deelnemende scholen. Zaken die worden verwezen en behandeld spelen zich alle binnen of in de directe omgeving van de school af. Alleen overtredingen begaan door leerlingen van de deelnemende scholen en begaan in of in de buurt van de school komen in aanmerking voor behandeling in de jongerenrechtbank. Daarbij gaat het om gedragingen die strafbaar zijn volgens het Wetboek van Strafrecht, maar ook om kleinere niet strafbare kwesties. In dit artikel geven de auteurs een beschrijving van de Nederlandse praktijk gedurende de eerste drie jaar en de eerste bevindingen en conclusies.

\section{Korte historie}

Het idee van een Nederlandse 'kinderrechtbank' werd in 2006 geboren tijdens een brainstorm van de toenmalige Stichting Kinderrechtenhuis

* Drs. G.J. Slump is criminoloog en landelijk projectleider voor de Stichting Jongerenrechtbanken Nederland. Hij heeft een eigen adviespraktijk voor projecten op strafrechtelijk gebied en geeft trainingen op het terrein van herstelrecht en herstelgericht werken. Prof. dr. J. Asscher is hoogleraar Forensische Orthopedagogiek aan de Universiteit Utrecht en hoofddocent aan de Universiteit van Amsterdam. Zij is lid van de Raad van Advies van de stichting Jongerenrechtbanken.

1 Voor een indruk zie de juniordocumentaire 'Zapp echt gebeurd - De jongerenrechtbank' van zondag 13 mei 2018. https://tvblik.nl/zpp-echt-gebeurd/de-jongerenrechtbank.

2 https://www.youthcourt.net. 
Nederland. Het bestuur zocht voor de opzet van het Kinderrechtenhuis Nederland, dat in 2008 in het weeshuiscomplex aan de Hooglandse Kerkgracht in Leiden gerealiseerd zou worden, passende projecten. Tijdens voorbereidingen werd van verschillende kanten gewezen op het feit dat er in de Verenigde Staten veel Youth Courts actief waren. Een aantal betrokkenen heeft deze bezocht.

Volgens tellingen van de 'National Association of Youth courts' functioneren er in de VS ruim 1.000 jongerenrechtbanken. ${ }^{3}$ Deze Youth Courts zijn geïnitieerd vanuit particulier initiatief; zij zijn meestal verbonden aan lokale rechtbanken of aan Community Justice Centers. In deze CJS's wordt de gemeenschap actief betrokken bij veiligheidsvraagstukken en richt de aanpak zich op het vergroten van de impact van de justitiële aanpak op buurten en wijken.

In Amerikaanse Youth Courts worden jongeren die overtredingen begaan verantwoordelijk gehouden voor hun gedrag door hun 'peers' (leeftijdgenoten) en als dit nodig is, krijgen de jongeren die de overtreding hebben begaan waar nodig ook toegang tot hulpverleningsprogramma's. De Nederlandse onderzoeker Suzan Verberk deed reeds in 2005 in opdracht van de Raad voor de rechtspraak - met het oog op de mogelijkheden van externe oriëntatie van de rechterlijke macht onderzoek naar de opzet van de vernieuwende rechtspraktijken, waaronder de Youth Courts in de VS (Verberk 2005).

Een verkenning van de Amerikaanse praktijk leverde op dat er verschillende modellen in omloop zijn. Het meest evidente onderscheid tussen die modellen betreft een onderscheid naar wie er recht spreekt: een jury van peers, een jongere die rechter is, een tribunaal dan wel een volwassen voorzitter die recht spreekt samen met jongeren. Andere verschillen zijn onder meer gelegen in het type zaken dat behandeld wordt en de programma's die jongeren worden aangeboden door de Youth Courts (Gaze 2016).

In 2011 kwam het idee in een stroomversnelling toen groepen die bezig waren met jongerenrechtbanken zich verbonden, en tegelijkertijd een aantal mensen uit de strafrechtelijke praktijk een werkbezoek bracht aan Red Hook Community Court in Brooklyn, NYC, en het daarin ondergebrachte Red Hook Youth Court. Beide zijn ontwikkeld in samenwerking met het Center for Court Innovation in New York. ${ }^{4}$

3 www.youthcourt.net/about/facts-and-stats.

4 www.courtinnovation.org. 
De ontwikkeling van jongerenrechtbanken in Nederland past binnen een aantal ontwikkelingen binnen onze samenleving. Een ervan is het feit dat de overheid en burgers op zoek zijn naar nieuwe onderlinge verhoudingen. Er is meer ruimte voor burgers om met eigen initiatieven te komen (buurtrechten, right to challenge) en te experimenteren binnen democratische grenzen. Verantwoordelijkheid en regie komen weer (meer) bij de burger te liggen.

Een andere daarop aansluitende ontwikkeling is die van herstelrecht en herstelgericht werken binnen het strafrecht. Daarbij gaat het om het bieden van de gelegenheid aan conflicterende partijen om, voorafgaand of tijdens een strafrechtelijke procedure, op vrijwillige basis samen uit een conflict te komen. Daarbij kan onder meer gedacht worden aan Halt, buurtbemiddeling of mediation in strafzaken. De jongerenrechtbank is een herstelrechtelijke toepassingsvorm waarbij gebruikgemaakt wordt van het rechtbankmodel.

Een derde ontwikkeling is die rond positieve veiligheid. Het 'bestrijden van onveiligheid' maakt plaats voor een benadering van veiligheid die ruimte geeft aan de behoefte van burgers aan een gemeenschappelijke basis waarin positieve noties als betrokkenheid, vertrouwen, empathie, verbondenheid en gezamenlijke waarden en normen centraal staan.

\section{Theoretische achtergrond en doelstellingen}

Jongerenrechtbanken worden verondersteld een positief effect te hebben op zowel daders als leden van de jongerenrechtbank zelf. Voor de dader geldt dat hij/zij via de jongerenrechtbank de kans krijgt het directe effect van zijn/haar gedrag op het slachtoffer te zien. Dit is zichtbaar in de slachtofferverklaringen, maar ook in de omschrijving hiervan door de rechter van de jongerenrechtbank (Stickle e.a. 2008). Een reden waarom jongerenrechtbanken positief effect zouden kunnen hebben, is de aanname dat de invloed van leeftijdgenoten groot is (Butts \& Buck 2002). Deze kan zowel negatief als positief ingezet worden en het doel van de jongerenrechtbanken is om de invloed van leeftijdgenoten op een positieve manier in te zetten. In die zin zou het proces juist voor de daders gunstig zijn omdat de sanctie wordt uitgesproken door leeftijdgenoten. De veronderstelling hierbij is dat straffen effectiever zouden zijn wanneer ze door leeftijdgenoten uitgespro- 
ken worden (Forgays \& Demilio 2005), omdat deze ervaren zouden kunnen worden als afwijzing van het deviante gedrag door leeftijdgenoten (Bouchard \& Wong 2017). Tijdens de adolescentie zijn leeftijdgenoten immers de belangrijkste rolmodellen (Furman \& Buhrmeester 1992), in zowel positieve als negatieve zin (Berndt 2002). Het gegeven dat de sancties opgelegd worden door leeftijdgenoten zou dus de kans op recidive doen afnemen (Forgays \& Demilio 2005).

Voor de leden van de jongerenrechtbank zelf is het een leerzame ervaring waarbij de kennis van het rechtssysteem toeneemt en ze leren verschillende belangen af te wegen. Daarnaast zou deelname aan jongerenrechtbanken bijdragen aan een gemeenschappelijke vergrote alertheid ten opzichte van delinquentie (Butts \& Buck 2000). Andere voordelen van de jongerenrechtbanken zijn dat het de belasting van het justitiesysteem zou beperken (Schneider 2008) en dat het relatief weinig kost (Butts \& Buck 2000). Afgezet tegen deze uitgangspunten kunnen jongerenrechtbanken een maatschappelijk nuttige en effectieve functie hebben in het Nederlandse onderwijsveld in verbinding met de omringende samenleving en het rechtsbestel.

De Nederlandse jongerenrechtbanken hebben de volgende kenmerken.

1. Jongerenrechtbanken zijn gestoeld op herstelrechtelijke uitgangspunten. In het herstelrecht is het uitgangspunt dat een strafbaar feit primair schade veroorzaakt tussen veroorzaker en benadeelde: het gaat erom dat de veroorzaker de schade die door zijn/haar toedoen is aangericht zelf vergoedt en dat geschonden relaties zodoende worden hersteld; straf is daaraan ondergeschikt. Jongeren zijn in staat het conflict (samen met leeftijdsgenoten) zelf op te lossen en de goede verhoudingen te herstellen (Godwin 2001).

2. Jongerenrechtbanken functioneren daarnaast vanuit het idee dat iemand die schade aanricht, daarmee de gemeenschap waartoe hij of zij behoort geweld aandoet/nadeel berokkent en dat hij/zij de schade herstelt of vergoedt met het doel de integriteit van die gemeenschap te herstellen. Verantwoordelijkheid voor de (school)gemeenschap waarvan leerlingen deel uitmaken, is een kernbegrip (Pearson 2003).

3. Leerlingen worden specifiek opgeleid om in verschillende rollen te kunnen functioneren. Dat heeft allereerst te maken met het feit dat zij zich zo de uitgangspunten van het herstelrecht toe-eigenen en 
zich bewust worden van de publieke verantwoordelijkheid binnen een gemeenschap. Verder maakt de jongerenrechtbank gebruik van een zorgvuldig ontwikkeld en op deze uitgangspunten gebaseerd zittingsprotocol dat zij moeten beheersen. Een opleiding van zeven dagdelen voorziet in de integratie van de Jongerenrechtbank in het onderwijs. Zo wordt concreet invulling gegeven aan een van de onderwijsdoelstellingen binnen het vak maatschappijleer, waarvan kennismaking met 'het recht' een (levend) onderdeel is en wordt (Stichting Jongerenrechtbanken Nederland 2018).

Kortom, de aanname is dat Jongerenrechtbanken zijn gebaseerd op de overtuiging dat je jongeren meer verantwoordelijkheid kunt geven, wanneer je hun daartoe ook het vertrouwen en de 'gereedschappen' geeft. Zo zouden zij in staat zijn binnen pedagogische grenzen zaken onderling met elkaar te bespreken en te behandelen in een omgeving waarin zij gestimuleerd worden om samen via morele oordeelsvorming besluiten te nemen in kwesties die op of rond de school spelen. Er is ook kritiek op de werkwijze van de jongerenrechtbanken. Allereerst richten jongerenrechtbanken zich op jongeren die kleine vergrijpen gepleegd hebben. In algemene zin geldt dat deze jongeren een laag recidiverisico hebben en dat deze delicten überhaupt niet in het justitiesysteem terechtgekomen zouden zijn. In die zin rijst de vraag of de hele inspanning die hoort bij een relatief klein vergrijp voor een jongerenrechtbank behandelen gerechtvaardigd is (Bouchard \& Wong 2017). Daarnaast is het mogelijk dat jongeren door de intensiteit en duur van een jongerenrechtbankprocedure langer en meer met hun daad geconfronteerd worden en zo zwaarder worden 'gestraft' dan in een reguliere justitiële procedure (Bouchard \& Wong 2017). Ten slotte laten de eerste overzichtsstudies geen duidelijk effect zien dat jongerenrechtbanken recidive verminderen (Bouchard \& Wong 2017; Gase, Schooley e.a. 2016).

\section{De pilot}

Aan de Nederlandse pilot die loopt van 1 januari 2015 tot en met 1 september 2018 nemen vier scholen deel. Dat zijn heel verschillende scholen. Ze zijn redelijk verspreid over Amsterdam (Zuidoost, Zuid (2) en West) en variëren van klein (Comenius Lyceum, 600 leerlingen) tot 
groot (Open Schoolgemeenschap Bijlmer, ruim 1.500 leerlingen) en van categoraal gymnasium (St. Ignatiusgymnasium) tot schoolgemeenschappen met diverse schooltypen (vmbo-T, havo, vwo). Met ingang van september 2018 neemt ook een school met een breed vmbo-aanbod deel (Wiringherlant College, Hollands Kroon).

$\mathrm{Er}$ is bewust gekozen voor een variatie aan scholen om de jongerenrechtbank in verschillende schoolomgevingen uit te testen.

\section{Werving en training leden jongerenrechtbank}

Jaarlijks worden er op de school voor jaarlaag 3 van het vmbo/havo en/of jaarlaag 4 van het havo/vwo één of meer informatiebijeenkomsten georganiseerd. Daarin vertellen de extern begeleider, leden van de jongerenrechtbank en een van de partners (rechtbank, OM, politie, advocatuur) wat een jongerenrechtbank is en hoe de werkwijze is. Vervolgens krijgen leerlingen de gelegenheid te solliciteren.

Leerlingen die worden toegelaten krijgen een training van zeven dagdelen van elk drie uur. Daarin zit ondermeer een bezoek aan de politie en de rechtbank, trainingen in communicatie- en bemiddelingsvaardigheden en het motiveren en opstellen van de uitspraak. Dit wordt afgesloten met het behandelen van oefenzaak in rechtbank en beëdiging door een rechter. De leden van de jongerenrechtbank ontvangen een theoriecertificaat en een speciaal T-shirt. De bedoeling is dat er per school op jaarbasis tien zaken worden behandeld. In de pilot is ervoor gekozen om bij gebrek aan zaken ${ }^{5}$ de jongerenrechtbank in een echte zitting zogenoemde oefenzaken (die op school hebben gespeeld of hadden kunnen spelen) te laten behandelen.

\section{Werkwijze selectie van zaken}

De jongerenrechtbank kan zowel strafbare feiten (Halt-waardige delicten en andere kleine vergrijpen) als niet-strafbare incidenten op school die tot nadeel voor medeleerlingen en/of de school leiden, behandelen. In geval van een strafbaar feit is voorwaarde dat de jongere niet eerder in beeld bij de politie is geweest bij een vergelijkbaar

5 Het eerste seizoen moesten de scholen duidelijk wennen aan de aanwezigheid van de jongerenrechtbank op school en het gegeven van 'een stap opzij doen' en een zaak onder verantwoordelijkheid van de school overlaten aan de jongerenrechtbank was niet altijd vanzelfsprekend. 
feit. In de Nederlandse jongerenrechtbanken wordt, anders dan in de Amerikaanse variant, een strafblad voorkomen. Omdat in de pilot wordt samengewerkt met de politie, is in een convenant tussen deelnemende partijen ${ }^{6}$ vastgelegd dat de politie in het kader van die samenwerking uitsluitend voor de pilot relevante informatie (namen van leerlingen, geregistreerd als 'betrokkenen', en aard van het incident, aard herstelacties) administreert. Deelname heeft geen strafrechtelijke gevolgen en mocht zich een (nieuw) strafbaar feit voordoen, dan staat bijvoorbeeld in voorkomende gevallen de weg naar Halt als 'first offender' gewoon open.

De selectie van zaken gaat als volgt. De coördinerend docent van de school (interne trekker) krijgt incidenten die op school spelen via het teamoverleg aangeleverd en overlegt met de afdelingsleider/teamleider over de geschiktheid van de zaak voor behandeling in de jongerenrechtbank. Indien nodig worden ook de zorgcoördinator en veiligheidscoördinator geconsulteerd. Belangrijke criteria zijn of de beschuldigde partij de betrokkenheid bij het incident erkent en of hij/ zij verantwoordelijkheid wil en kan nemen voor de daad/daden en dat alle partijen vrijwillig willen deelnemen. De zittingsbegeleider van de Stichting Jongerenrechtbanken Nederland die de zittingen altijd begeleidt en samenwerkt met de coördinerend docent kan worden geraadpleegd om vast te stellen of een zaak inderdaad geschikt is.

In geval van een (vermoedelijk) strafbaar feit neemt de coördinerend docent telefonisch contact op met de politie en bespreekt informeel en vertrouwelijk de zaak. De politie registreert dit contact in haar mutatiesysteem. Doel van het overleg is ook om te kijken of er contraindicaties zijn om de zaak waarbij de bewuste jongere betrokken is, niet aan de Jongerenrechtbank voor te leggen. Indien een jongere bijvoorbeeld eerder in beeld is geweest bij de politie voor vergelijkbare zaken, kan dit een reden zijn om de zaak af te wijzen voor behandeling.

\section{Zitting en zittingsvoorbereiding}

De zittingsvoorbereiding vindt meestal plaats op de dag van de zitting en de zitting zelf verloopt volgens een vastgesteld script. De uitspraak 
wordt aansluitend op de zitting gedaan en ook zo veel mogelijk ter plekke op schrift gesteld en uitgereikt aan betrokkenen.

In de uitspraken worden herstelacties opgenomen die de betrokkenen tijdens de zitting zelf voorstellen. Voorbeelden van herstelacties zijn het aanbieden van excuses, het meehelpen tijdens de open dag van de school, het helpen van de conciërge voor of na schooltijd, het houden van een spreekbeurt over een onderwerp gerelateerd aan de gebeurtenis (pesten of de gevaren van vuurwerk) en het betalen van een bedrag ter vergoeding van de schade.

\section{Resultaten van de pilot in cijfers}

Tot op heden:

- zijn er in de periode 2015-2018 91 zaken door de jongerenrechtbank behandeld in 54 echte zaken en 37 oefenzaken;

- zijn er in die 91 zaken in totaal 120 uitspraken gedaan (soms meerdere beschuldigden per zaak);

- zijn er in de periode 2015-2018 in totaal 147 leerlingen opgeleid als leden van de jongerenrechtbank;

- zijn in seizoen 2017-2018 48 leerlingen opgeleid als leden van de jongerenrechtbank;

- zijn in seizoen 2017-2018 in totaal 92 opgeleide leden van de jongerenrechtbank beschikbaar.

De meest voorkomende zaken zijn diefstallen, beledigingen/bedreigingen, mishandelingen of vechtpartijen, valsheid in geschrifte (valse verzuimbriefjes met name) en verboden wapenbezit (vaak niet van echt te onderscheiden nepwapens als BB guns. Ongeveer driekwart van de zaken betreft strafbare feiten en de rest betreft geen strafbare maar vervelende kwesties (zoals de orde verstoren in de klas of misbruik van het alarm, gebruik lachgas in de klas).

Twee onderzoeken begeleiden de pilot: een onderzoek van de Universiteit Leiden (programma- en procesevaluatie) en een onderzoek van Motivaction (normen- en waardenonderzoek).

De eerste tussenmeting van de Universiteit Leiden (Rap e.a. 2016) wijst uit dat de doelgroep van de jongerenrechtbank wat betreft de beschuldigden voornamelijk bestaat uit jongens tussen de twaalf en zestien jaar oud, die in de eerste vier leerjaren zitten. 
Uit de eerste meting van Motivaction (Königs \& Ait Moha 2016) bleek dat de jongerenrechtbanken na een klein jaar bij $60 \%$ van de leerlingen op de deelnemende scholen bekend waren. Met name de werving op school leidt tot brede bekendheid. Uit de tweede meting van Motivaction een jaar later (Königs \& Ait Moha 2017) blijkt dat de bekendheid van de jongerenrechtbanken in het tweede jaar is gestegen van 60 naar $67 \%$, nog steeds een voorzichtig percentage overigens dat aandacht vereist. Zo wordt gedacht aan inhoudelijke voorlichting over jongerenrechtbanken en 'voorbeeldzittingen' voor de onderbouw. Ongeveer $80 \%$ van de leerlingen lijkt de algemene doelstelling van de jongerenrechtbank te steunen.

Ook de specifieke doelen van een jongerenrechtbank worden onderschreven:

- beter leren conflicten op te lossen (92\%);

- meer kennis krijgen over gelijkwaardigheid en democratie (90\%);

- vaardigheden ontwikkelen om actief mee te doen in een groep (89\%);

- actief betrokken zijn bij de school (76\%).

Het veiligheidsgevoel op de vier scholen blijkt iets te zijn gestegen ten opzichte van de eerste meting.

\section{Onderzoek Universiteit Leiden: onderbouwing en verbetering}

De Afdeling jeugdrecht van de Universiteit Leiden is gevraagd onderzoek te doen naar de theoretische onderbouwing en een procesevaluatie te verrichten. Daarbij wordt gekeken naar werkzame elementen en zaken die voor verbetering vatbaar zijn. De onderzoekers deden een literatuuronderzoek en bestudeerden het materiaal van de jongerenrechtbanken. Ook zijn zittingen geobserveerd en betrokkenen geïnterviewd.

Een eerste tussentijdse onderzoeksrapportage is verschenen en medio 2018 wordt het onderzoek afgerond. Het onderzoek zal als een van de bronnen dienen voor een binnenkort in te dienen verzoek bij de Erkenningscommissie Justitiële Interventies.

Uit het onderzoeksdeel dat ingaat op de theoretische onderbouwing (Rap e.a. 2016) komt naar voren dat verschillende studies uit de Verenigde Staten ingaan op de effectiviteit van jongerenrechtbanken en 
wisselende resultaten geven waar het gaat om het voorkomen van recidive. Overigens is om die reden de doelstelling van de jongerenrechtbanken in Nederland verbreed en zijn ook andere positieve parameters die kunnen wijzen op effectiviteit benoemd.

Het accent in de eerste tussenrapportage lag op het benoemen van knel- en verbeterpunten. In het tweede en derde pilotjaar zijn die punten geïmplementeerd en tevens is op basis daarvan een handleiding voor de scholen geschreven. De bedoeling is dat die handleiding (in het kader van een samenwerkingsovereenkomst tussen de Stichting Jongerenrechtbanken en de scholen) in het vervolgjaar 2018-2019 leidend is voor de jongerenrechtbankpraktijken.

\section{Onderzoek Motivaction: normen- en waardenbeleving onder leerlingen}

Motivaction is gevraagd een onderzoek te doen naar de normen- en waardenbeleving door leerlingen op de deelnemende scholen (en controlescholen) om uitspraken te kunnen doen ten aanzien van de vraag of jongerenrechtbanken aansluiten op die beleving. Daartoe zijn alle leerlingen aangeschreven om aan de hand van een digitale vragenlijst antwoord te geven op speciaal voor dit onderzoek ontwikkelde stellingen en hun mening te geven over de afhandeling van een aantal concrete incidenten.

De doelstellingen van de jongerenrechtbank zijn in stellingvorm aan de leerlingen voorgelegd en worden door leerlingen op de scholen in grote lijnen onderschreven. Zo geven zij aan te vinden dat bij kleine vergrijpen de kans op herhaling kleiner is als leerlingen zelf de oplossing kunnen aandragen om de fout goed te maken. Bij grotere vergrijpen denken zij echter dat de kans op herhaling juist weer minder klein is en de kans op een rechtvaardige oplossing minder groot als leerlingen de oplossing zelf aandragen. Ook denken zij dat zijzelf betere oplossingen kunnen bedenken wanneer zij iets goed te maken hebben (zelfbeschikking en herstelrecht). Ten slotte blijkt uit de resultaten dat leerlingen op de vier scholen over het algemeen beschikken over een grote mate van gemeenschapszin, gevoel voor rechtvaardigheid en verantwoordelijkheid. De ondervraagde jongeren hebben minder op met autoriteit van buitenaf. Zij vinden overigens duidelijke regels wel belangrijk, net als het stellen van grenzen. Overigens zijn ze daarbij 
weer tolerant ten opzichte van overtredingen. De meeste leerlingen vinden dat iedereen zo af en toe de fout in mag gaan.

26 bij de jongerenrechtbanken betrokken leerlingen hebben deelgenomen aan een verdiepend deel van het onderzoek (Azaaj, Wolff Schoemaker e.a. 2018). Uit het verdiepend deel komen vooral positieve associaties rond de jongerenrechtbank naar voren zoals beter leren communiceren, elkaar kunnen helpen en samen werken aan rechtvaardigheid. Wel geven leerlingen aan dat ze niet tevreden zijn over het aantal zaken dat is aangemeld door hun school.

Leerlingen die als lid van de jongerenrechtbank deelnamen, zijn positief over het opleidingstraject en de leeropbrengst van deelname aan de jongerenrechtbank. Zowel leden als beschuldigden en benadeelden waarderen het idee van jongerenrechtbanken positief: het draagt volgens hen bij aan het goede imago van de school. Daarnaast zijn zij expliciet in het benadrukken dat het een mogelijkheid is om op een manier die past bij het incident 'fouten' te herstellen en toekomstig negatief gedrag te voorkomen.

Ten slotte spreekt het idee 'door jongeren, voor jongeren' aan omdat in de optiek van deelnemende leerlingen jongeren bij conflicten of problemen liever met hun eigen leeftijdsgenoten praten dan met volwassenen. Enkele reacties van jongeren:

'Als je iemand een maatregel oplegt die ervoor zorgt dat de schade die ontstaan is wordt hersteld heeft iedereen daar meer aan dan als er een straf wordt gegeven door een leraar en er vervolgens niets gebeurt om de relatie tussen beschuldigde en benadeelde te verbeteren. Bovendien praten jongeren veel liever met andere jongeren over problemen dan met ouderen.' (lid jongerenrechtbank)

'Vaak vind ik straffen overbodig. Als je iets fout hebt gedaan ben je wel volwassen genoeg om dat in te zien. Zodra mensen er een straf aan vast gaan binden maken ze het alleen maar erger.' (benadeelde)

'Heel goed. Tijdens mijn zaak zaten 6de-klassers de rechtszaak voor en zij konden mij en mijn vrienden veel beter begrijpen dan de school. Daarom zullen zij er ook heel anders over denken en handelen.' (beschuldigde) 


\section{Conclusies}

Concluderend kan worden gesteld dat met de werkzaamheden van de Stichting Jongerenrechtbanken Nederland een geheel eigen Nederlandse variant van de Amerikaanse Youth Courts is ontwikkeld. Er is geïnvesteerd in onderzoek (30\% van de projectkosten) om de praktijk kritisch te volgen en verder te ontwikkelen.

De belangrijkste kracht van jongerenrechtbanken is de combinatie van herstelrecht, het ontwikkelen van kennis en procedurele vaardigheden rondom de procesgang (door leden van de jongerenrechtbank) en de rol van peers/jongeren zelf. Wat betreft dat laatste kan in de opbouw (begeleiding) en organisatie van jongerenrechtbanken nog meer winst geboekt worden.

$\mathrm{Na}$ drie jaar van pilots hebben onderzoeksrapporten tal van verbeterpunten aangedragen die tot discussie aanleiding geven en zijn of zullen worden doorgevoerd. Ook is gekeken naar de normen- en waardenbeleving van leerlingen op deelnemende scholen. De inzet van jongerenrechtbanken sluit aan bij wat jongeren zelf aandragen aan oplossingsrichtingen bij incidenten op scholen en zit in de beleving van jongeren als besluitvormingsmodel in tussen het vermogen om 'zelf af te doen' (inzet van een jongerenrechtbank hoeft niet altijd) en 'formeel afdoen door volwassenen' (inzet van een jongerenrechtbank kan niet altijd).

De instroom van zaken laat nog te wensen over. Wellicht kan verbetering optreden door de aanmelding van zaken niet langer via de schoolleiding te laten verlopen, maar rechtstreeks door leerlingen zelf. De resultaten van de eindrapportages van beide onderzoeken, die worden verwacht in de zomer van 2018, zullen worden gebruikt bij de verdere uitrol van het project in Amsterdam, waar de komende twee jaar tien scholen gaan meedoen. Ook de jongerenrechtbank in Hollands Kroon gaat in 2018 van start.

Rond het fenomeen jongerenrechtbanken blijven nog verschillende discussiepunten actueel. Zo is het de vraag of er pedagogische grenzen zijn aan het model van jongerenrechtbanken: wat kun je wel en niet aan jongeren ter besluitvorming overlaten? Welke randvoorwaarden zijn nodig om jongeren veilig ${ }^{7}$ te laten deelnemen en op welke wijze zouden volwassen begeleiders ondersteuning kunnen bieden? Voorts

7 Hier wordt niet gedoeld op het aspect 'secure' maar op het aspect 'safe'. 
is nadere reflectie geboden op de positie van jongerenrechtbanken ten opzichte van het strafrecht. Ten slotte is het interessant om te bekijken hoe de verhouding tussen burgers en overheid zich in de komende jaren gaat ontwikkelen en welke kansen dat biedt voor burgerschapsvorming van jongeren.

\section{Literatuur}

\section{Azaaj e.a. 2018}

I. Azaaj, F. Wolff Schoemaker \& R. Thijssen, Betrokken leerlingen over jongerenrechtbanken: Een kwalitatieve verdieping onder leden, beschuldigden en benadeelden, Amsterdam: Motivaction 2018.

\section{Berndt 2002}

T.J. Berndt, 'Friendship and social development', Current Directions in Psychological Science 2002, nr. 11, p. 7-10.

\section{Bouchard \& Wong 2017}

J. Bouchard \& J. Wong, 'A jury of their peers: A Meta-Analysis of the effects of teen court on criminal recidivism', Journal of Youth and Adolescence 2017, nr. 46, p. 1472-1487.

\section{Butts \& Buck 2000}

J.A. Butts \& J. Buck, Teen Courts:

A Focus on Research (OJJDP Juvenile Justice Bulletin), Washington, DC: Office of Juvenile Justice and Delinquency Prevention, US Department of Justice 2000.

\section{Butts e.a. 2002}

J. Butts, J. Buck \& M. Coggeshall, The impact of Teen Court on young offenders: Research report, Urban Institute Justice Policy Center 2002.

\section{Forgays \& Demilio 2005}

D.K. Forgays \& L. Demilio, 'Is Teen Court Effective for Repeat Offenders? A Test of the Restorative Justice Approach', International Journal of Offender Therapy and Comparative Criminology 2005, nr. 1, p. 107-118.

\section{Furman \& Buhrmeester 1992}

Q. Furman \& D. Buhrmeester, 'Age and Sex Differences in Perceptions of Networks of Personal Relationships', Child Development 1992, nr. 63, p. 103-115.

\section{Gase e.a. 2016}

L.N. Gase, T. Schooley, A. DeFosset, M.A. Stoll e.a., 'The Impact of Teen Courts on Youth Outcomes: A Systematic Review', Adolescent Research Review 2016, nr. 1, p. 51-67. 


\section{Godwin 2001}

T.M. Godwin, The role of restorative justice in Teen Courts: A preliminary look, Lexington (KY): National Youth Court Center (NYCC), American Probation and Parole Organization 2001.

\section{Königs \& Ait Moha 2016}

M. Königs \& A. Ait Moha, Normen en waarden onder jongeren naar aanleiding van de jongerenrechtbanken, Amsterdam: Motivaction 2016.

\section{Königs \& Ait Moha 2017}

M. Königs \& A. Ait Moha, Vervolgmeting: Normen en waarden onder jongeren naar aanleiding van de jongerenrechtbanken, Amsterdam: Motivaction 2017.

\section{Pearson 2003}

S.S. Pearson, 'Youth court - A path to civic engagement', National Youth Court Policy Brief september 2003, National Youth Court Center (NYCC), American Probation and Parole Organization 2003.

\section{Rap e.a. 2016}

S. Rap, A. Bolscher, D. Verkroost \& I. Mijnarends, Een procesevaluatie van de pilot jongerenrechtbanken, Leiden: Universiteit Leiden 2016.

\section{Schneider 2008}

J. Schneider, Youth courts: An empirical update and analysis of future organizational and research needs, Washington, DC: George Washington University 2008. www.ncjrs.gov/pdles1/ ojjdp/grants/222592.pdf.

\section{Stichting Jongerenrechtbanken} Nederland 2018

Stichting Jongerenrechtbanken

Nederland, Trainingsprogramma 2018-2019, Amsterdam 2018.

\section{Stickle e.a. 2008}

W.P. Stickle, N.M. Connell, D.M. Wilson \& D. Gottfredson, 'An experimental evaluation of teen courts', Journal of Experimental Criminology 2008, nr. 2, p. 137-163. https://doi.org/10.1007/ s11292-008-9050-8

\section{Verberk 2005}

S. Verberk, Rechter onder de mensen? Over de externe oriëntatie van de rechterlijke macht in Californië, Den Haag: Raad voor de rechtspraak 2005. 